\title{
Soğuk Metal Transfer (CMT) ve Darbeli Soğuk Metal Transfer (Darbeli CMT) Kaynak İşlemleri ile Birleştirilmiş AA5754 Alüminyum Alaşımının Mikroyapı ve Mekanik Özelliklerinin Karşılaştırmalı Olarak İncelenmesi
}

\section{Fatih KAHRAMAN*1, Gökçe Mehmet GENÇER ${ }^{1}$, Coşkun YOLCU¹, Ayça Demirer KAHRAMAN $^{2}$, Mehmet Ege DÍLBAZ ${ }^{1}$}

${ }^{1}$ Dokuz Eylül Üniversitesi, Mühendislik Fakültesi, Makine Mühendisliği Bölümü, 12345, İzmir. (ORCID: 0000-0002-1075-9171),(ORCID: 0000-0003-1084-7240), (ORCID: 0000-0001-7335-3091),(ORCID: 0000-0001-7533-7706)

2Manisa Celal Bayar Üniversitesi, Mühendislik Fakültesi, Makine Mühendisliği Bölümü, 45140, Manisa. (ORCID: 0000-0002-1044-7389)

(Alınış / Received: 15.11.2017, Kabul / Accepted: 29.12.2017, Online Yayınlanma / Published Online: 15.05.2018)

\begin{abstract}
Anahtar Kelimeler Özet: Alüminyum alaşımlarının ergitme kaynağı yöntemleri ile AA5754, Darbeli CMT ișlemi, Mikroyapı, Isll girdi kaynak edilebilirliği oldukça düşüktür. Bu nedenle bu çalışmada AA5754 alüminyum alaşımının kaynak edilebilirliği farklı işlem parametrelerinde (farklı ısı girdisi) CMT ve Darbeli CMT kaynak yöntemleri kullanılarak incelenmiştir.
\end{abstract}

CMT kaynak yöntemi kullanılarak yapılan kaynaklı bağlantılarda meydana gelen gözeneklerin hem boyutları ve hem de dikiş içerisindeki miktarı Darbeli CMT kaynak yönteminde elde edilenlere göre daha fazladır. Benzer şekilde nüfuziyet eksikliği hatası da darbeli CMT kaynak yönteminde daha az oluşmaktadır. Diğer bir deyişle Darbeli CMT kaynak yöntemi daha yüksek nüfuziyete sahiptir. Her iki yöntemde de verilen ısı girdisinin artışına bağlı olarak bu hataların oluşumu azalmaktadır. Her iki yöntemde de ısı girdisinin artışı ITAB'da kaynak metaline yakın bölgelerde tane irileşmesine neden olmaktadır. Ancak aynı miktardaki ısı girdisi uygulandığında CMT yönteminde daha fazla tane irileşmesi meydana gelmektedir. Kaynaklı bağlantıların mekanik dayanımları karşılaştırıldığında, Darbeli CMT kaynak yöntemi ile elde edilmiş kaynaklı bağlantıların mekanik özelliklerinin daha yüksek olduğu tespit edilmiştir. Gerek daha küçük ebatlı ve daha az kaynak hatası oluşması ve gerekse ITAB'da daha ince tane oluşması, Darbeli CMT kaynak yönteminde elde edilen bağlantıların mekanik dayanımlarının daha yüksek olmasını sağlamıştır. 
F. Kahraman vd. / Soğuk Metal Transfer (CMT) ve Darbeli Soğuk Metal Transfer (Darbeli CMT) Kaynak İșlemleri ile Birleștirilmiș AA5754 Alüminyum Alașımının Mikroyapı ve Mekanik Özelliklerinin

Karşılaştırmalı Olarak İncelenmesi

\title{
Comparative Examination of Microstructure and Mechanical Properties of AA5754 Aluminum Alloy Joined with Cold Metal Transfer (CMT) and Pulsed Cold Metal Transfer (Pulsed CMT) Welding Processes
}

\author{
Keywords \\ AA5754 \\ Pulsed CMT \\ process, \\ Microstructure, \\ Thermal input

\begin{abstract}
Aluminum alloys have poor weldability with fusion welding methods. For this reason, the weldability of AA5754 aluminum alloy was investigated with various process parameters (various thermal input) by using CMT and Pulsed CMT welding processes.
\end{abstract}

Both sizes and quantities of occurring pores in the welded joints by using CMT process are greater than occurring pores in Pulsed CMT process. Similarly, the lack of penetration defect also forms less frequently in the Pulsed CMT process. In other word, Pulsed CMT welding process has better penetration. The formation of these defects decreases depending on the increase in thermal input that were given in both of these methods. In both of these methods, the increase in thermal input cause grain growth in the near regions of welding seam in HAZ. However, the same amount of thermal input was applied, more grain growth occurred in CMT process. When the mechanical strengths of the welded joints are compared, it was determined that the mechanical properties of welded joints obtained by Pulsed CMT process are higher. Either the formation of smaller sized and less welding defect, or formation of finer grains in HAZ provide to obtain higher mechanical strengths of the joints welded by Pulsed CMT welding process.

*fatih.kahraman@deu.edu.tr

\section{Giriş}

Alüminyum alaşımları makine konstrüksiyonu, otomotiv, havacilık vb. sanayi ve teknoloji alanlarında; yüksek korozyon direnci, hafifliği, yüksek ısı ve elektrik iletkenliği ve iyi mekanik özellikleri ile geniş kullanım alanı bulmaktadır $[1,2]$. Özellikle otomotiv ve havacılık endüstrisinde çevreyi koruma amaciyla hafif metallerin kullanımı üzerine daha çok çalışmalar yapılmaktadır [3]. Alüminyum alașımlarının hafif ve dayanıklı olușları (özgül mukavemetlerinin yüksek oluşu) daha ince levhaların/profillerin kullanımına imkân sağlamaktadır. Bu nedenle, imal edilecek konstrüksiyonda ağırlık artışına izin vermeyecek şekilde (cıvata, somun, perçin vb. makine elemanları kullanılmadan) alüminyum alaşımı ince levhaların/profillerin kaynakla birleştirilmesi büyük öneme sahiptir [2, 4].

Alüminyumun sahip olduğu bazı özellikler ark kaynağı yöntemleri ile alüminyum alaşımlarının kaynak kabiliyetini azaltmaktadır. Bu özellikler, alaşım yüzeyinde yüksek ergime sıcaklığına ve yalıtkanlığa sahip oksit tabakasının bulunması, sıcak yırtılma riski, yüksek ısıl iletkenlik, yüksek termal genleșme katsayısı sebebiyle kaynak dikişinde çarpılma ve çatlak oluşumu ve yüksek iç gerilmelerin oluşumu olarak verilebilir [5]. Bu özellikler nedeniyle alüminyum alaşımlarının kaynağını ergitme kaynağı yöntemleri ile 
F. Kahraman vd. / Soğuk Metal Transfer (CMT) ve Darbeli Soğuk Metal Transfer (Darbeli CMT) Kaynak İșlemleri ile Birleștirilmiș AA5754 Alüminyum Alașımının Mikroyapı ve Mekanik Özelliklerinin

Karşılaştırmalı Olarak İncelenmesi

gerçekleştirmek zordur. Günümüzde, devre, kutuplamanın kontrolü ve tel yüksek dayanımlı alüminyum alaşımı birleştirmeleri elde etmek için sürtünme karıştırma kaynağı ve difüzyon kaynağı gibi katı hal kaynağı yöntemleri kullanılmaktadır [6, 7]. Ancak, katı-hal kaynak yöntemlerinin özel konstrüktif birleştirmelerdeki düşük uygulanabilirliği (yöntemlerin esnek olmayışı) ve buna ek olarak difüzyon kaynağ duyulması, yöntemlerin kullanımlarını kısitlamaktadır [6]. Uygulama kolaylıkları nedeniyle konvansiyonel TIG (tungsten inert gaz) ve MIG (metal inert gaz) kaynağı alüminyum alaşımlarının kaynağında sıklıkla kullanılmaktadır. Ancak, bu yöntemlerle ince levhaların birleştirilmesinde nüfuziyetin kontrol edilememesi levhaların delinmesine ya da uygun birleştirmenin elde edilememesine neden olmaktadır [3]. $\mathrm{Bu}$ nedenle, özellikle ince levhaların kaynağında ısı girdisi daha düşük olacak şekilde kaynak işlemi yapılmaya çalışılmaktadır.

Kaynaklı imalatta ısıl girdinin azaltılması her zaman için rağbet gören araştırma alanı olmuştur [8, 9]. Günümüzde bu amacı sağlayabilecek MIG kaynak yöntemine entegre edilmiş CMT (Cold Metal Transfer), Darbeli-CMT, Geliștirilmiș CMT, Geliștirilmiș DarbeliCMT, Dinamik-CMT vb. gibi "soğuk" ark kaynağı yöntemleri mevcuttur. Bu yöntemler, ergimiş malzemenin transferinin optimizasyonuyla isıl girdiyi hareketinin ayarlanması gibi çeşitli temel prensiplere dayanmaktadır [10, 5]. Düşük ısıl girdi ile kaynak işlemi özellikle otomotiv, uzay ve uçak gibi büyük sanayi dallarında uygulama alanı bulan farklı metallerin birbiri ile ve çok ince levhaların kaynakları gibi zor olan kaynak işlemlerini mümkün kılmaktadır.

CMT kaynak işleminde, ark boyunun, metal transferi miktarının ve ısıl girdi miktarının kontrolü için yüksek hızlı dijital kontrol sistemine entegre edilmiş bir tel elektrod sürme sistemi mevcuttur. Konvansiyonel MIG/MAG kaynağında kaynakta kısa devre oluşana kadar tel elektrod sürülmeye devam eder. Kısa devre oluşup kaynak akımı çok yükseldiğinde ise, kaynak bölgesine yüksek ısıl girdi gerçekleşir ve bu nedenle de sıçramalar meydana gelir. CMT kaynağında ise metal transferi sırasında gerçekleşen her kısa devrede, dijital kontrol sistemi kaynak akımını düşürür ve tel elektrodun geri çekilmesini kontrol eder $(70 \mathrm{~Hz}$ 'e kadar titreşimli tel elektrod besleme) [5]. Tel elektrodun geri çekilme hareketi kısa devre süresince damla geçişine yardım eder. Böylece, elektromanyetik kuvvetin yardımı olmadan, metal kaynak banyosuna transfer edilir (Şekil 1). Bu şekilde kaynak bölgesindeki ısıl girdi büyük ölçüde azaltılmış olur [3]. Damla transferinden sonra ark yeniden ateşlenir ve tel elektrod tekrar ileri sürülür (döngü tekrar başlar). azaltan güç kaynağı regülasyonu, kısa

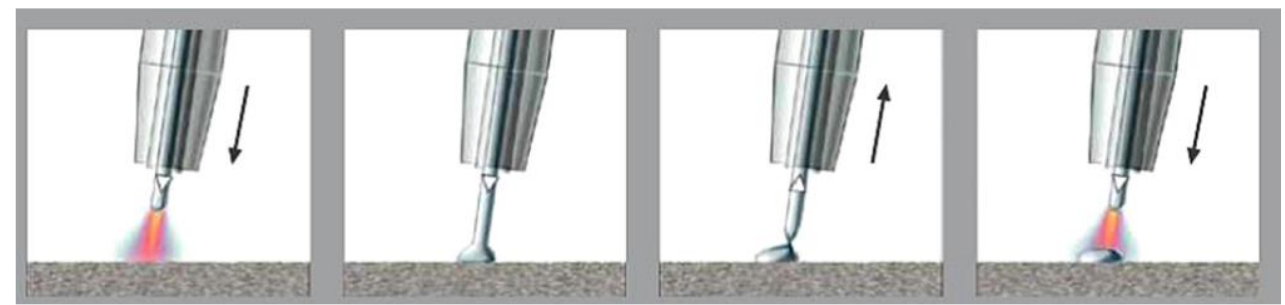

Şekil 1. CMT kaynağının aşamaları [11] 
F. Kahraman vd. / Soğuk Metal Transfer (CMT) ve Darbeli Soğuk Metal Transfer (Darbeli CMT) Kaynak İşlemleri ile Birleştirilmiş AA5754 Alüminyum Alaşımının Mikroyapı ve Mekanik Özelliklerinin Karşılaștırmalı Olarak İncelenmesi

a)

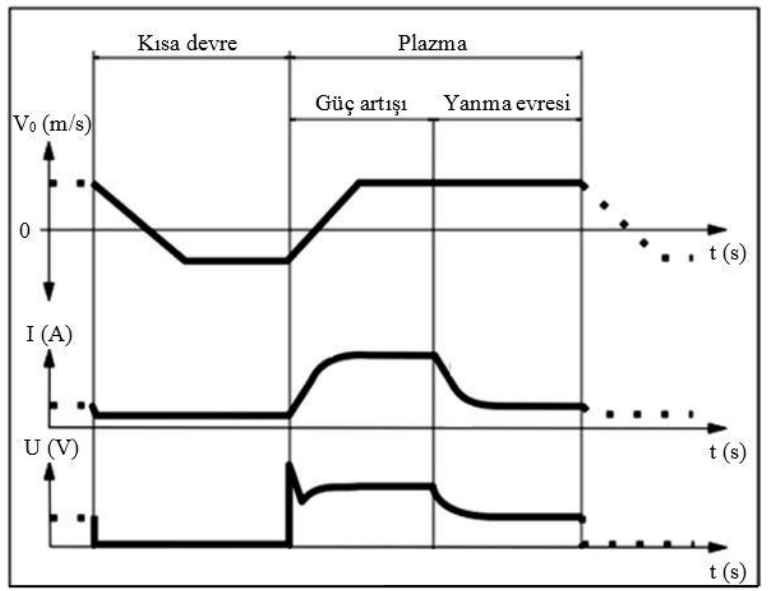

b)

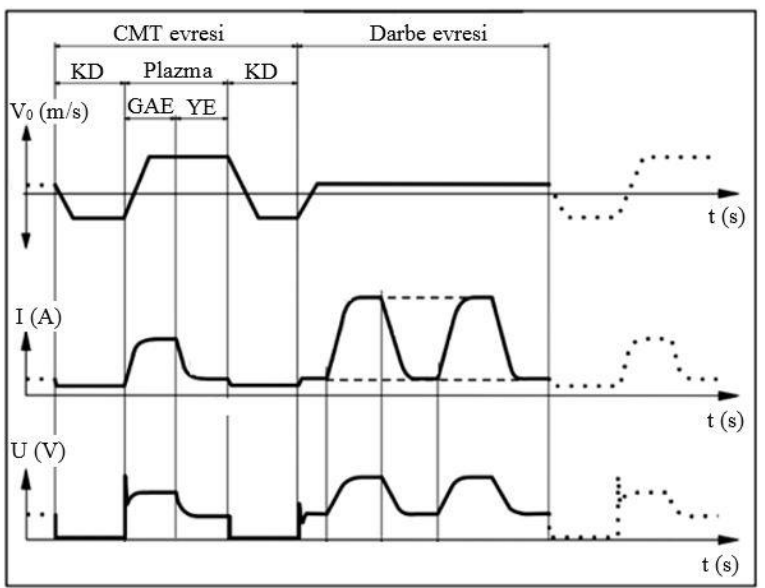

Şekil 2. CMT ve Darbeli CMT yöntemlerine ait akım-zaman, gerilim-zaman ve tel sürme hızızaman eğrileri; (a) CMT yöntemi karakteristik eğrileri; (b) Darbeli-CMT yöntemi karakteristik eğrileri (KD: Kısa devre; GAE: Güç artış evresi; YE: Yanma evresi) [10]

Günümüzde CMT kaynağı; yüzey kaplama, hızlı ya da yavaş kaynak yapabilme, kaynak dikiş formunun ayarlanabilmesi gibi farklı karakteristiklerde uygulamalara cevap verecek șekilde farklı çalıșma prensipleri ile geliştirilmiştir. Bunlardan biri Darbeli-CMT kaynağıdır. Darbeli-CMT kaynağında, prosese darbeli akımın uygulandığı döngü de eklenir. Bu durum, normal CMT kaynağına oranla daha fazla ısıl girdi oluşturur ve dolayısıyla DarbeliCMT kaynağında daha yüksek kaynak hızları kullanılabilir. Darbeli-CMT kaynağında; normal CMT kaynağındaki döngüler arasına darbeli akımlar uygulanabilmektedir. $\mathrm{Bu}$ aşamada tel elektrod ileri sürülerek kaynak banyosuna damla geçiși sağlanır ve ark söner. Sönen ark tekrar ateşlenerek normal CMT süreci tekrar başlatılır [10]. CMT döngüleri arasında uygulanan darbeli akımın frekansının ayarlanması ile gerekli uygulama için optimum değerler seçilebilmektedir. Şekil 2'de normal CMT ve Darbeli-CMT kaynağına ait grafikler gösterilmiştir. CMT kaynağ alüminyum ve magnezyum alaşımlarının ince levha kaynaklarında kullanılan yeni bir yöntem olduğu için literatürde yöntemle yapılan çalışmaların sayısı oldukça azdır. Darbeli CMT kaynağı ise en yeni ergitme kaynağı yöntemlerinden birisidir. Bu nedenle darbeli CMT kaynak 
F. Kahraman vd. / Soğuk Metal Transfer (CMT) ve Darbeli Soğuk Metal Transfer (Darbeli CMT) Kaynak İșlemleri ile Birleștirilmiș AA5754 Alüminyum Alaşımının Mikroyapı ve Mekanik Özelliklerinin Karşılaştırmalı Olarak İncelenmesi

yöntemi ile yapılan çalışmalar ise çok açısı $60^{\circ}$ olacak şekilde V kaynak ağızları daha azdır. Çalıșmamızda normal CMT ve açılmıștır. Kaynak ișlemi için Fronius Darbeli-CMT kaynak yöntemleri ile TransPuls Synergic 5000 CMT cihazı birleștirilmiș AA5754 kaynaklı bağlantıların mekanik özellikleri ve kaynak bölgesinde oluşan içyapıları üzerine kaynak parametrelerinin etkileri karşılaştırmalı olarak incelenmiştir.

\section{Materyal ve Metot}

Çalışmada 3 mm kalınlığında AA5754H111 esas malzeme olarak kullanılmıştır. AA5754 alaşımının kimyasal kompozisyonu Tablo 1'de verilmiștir. Kaynak edilecek levhalar $3 \times 150 \times 150$ mm'lik boyutlarda hazırlanmış ve levhalara kök yüksekliği $1 \mathrm{~mm}$ ve ağız

kullanılmıștır. Levhalar tek pasoda robotik CMT-MIG ve Darbeli CMT-MIG yöntemi kullanılarak birleştirilmiştir. Kaynak işlemlerinde kimyasal kompozisyonu Tablo 2'de verilen 1,2 mm çaplı ER5183 tel elektrod kullanılmıștır. Koruyucu gaz olarak \%100 argon kullanilan deneylerin kaynak parametreleri Tablo 3'de verilmiștir. Kaynak için hazırlanan levhalar arada boşluk kalmayacak şekilde alın alına getirilmiş ve çelik pabuçlar ile rijit bir şekilde sabitlenmiştir (Şekil 3).

Tablo 1. AA5754 alașımının kimyasal kompozisyonu

\begin{tabular}{cllllllllllll}
\hline & Al & Si & Fe & Cu & Mn & Mg & Ni & Zn & Pb & Sn & Ti & Diğer \\
\hline \multirow{2}{*}{ Değerler } & Kalan & 0,5 & 0,5 & 0,1 & 0,5 & $2,5-$ & 0,05 & 0,2 & 0,05 & 0,05 & $0,05-$ & $0,05-$ \\
& & & & & & 3,5 & & & & & 0,25 & 0,15 \\
\hline
\end{tabular}

Tablo 2. ER5183 elektrodun kimyasal kompozisyonu

\begin{tabular}{ccccccccccc}
\hline & Al & $\mathbf{S i}$ & $\mathbf{F e}$ & $\mathbf{C u}$ & $\mathbf{M n}$ & $\mathbf{M g}$ & $\mathbf{C r}$ & $\mathbf{Z n}$ & $\mathbf{T i}$ & Diğger \\
\hline \multirow{2}{*}{ Değerler } & Kalan & 0,4 & 0,4 & 0,1 & $0,5-$ & $4,3-$ & $0,05-$ & 0,25 & 0,15 & $0,05-$ \\
& & maks. & maks. & maks. & 1 & 5,2 & 0,25 & maks. & maks. & 0,15 \\
\hline
\end{tabular}

Tablo 3. Kaynak parametreleri

\begin{tabular}{ccccccc}
\hline $\begin{array}{c}\text { Numune } \\
\text { Numarası }\end{array}$ & $\begin{array}{c}\text { Kaynak } \\
\text { Prosesi }\end{array}$ & $\begin{array}{c}\text { Akım } \\
\text { (A) }\end{array}$ & $\begin{array}{c}\text { Voltaj } \\
\text { (V) }\end{array}$ & $\begin{array}{c}\text { Tel Sürme } \\
\text { Hızl } \\
\text { (m/d) }\end{array}$ & $\begin{array}{c}\text { Kaynak } \\
\text { Hızı } \\
\text { (cm/d) }\end{array}$ & $\begin{array}{c}\text { Isı Girdisi } \\
\text { (kJ/mm) }\end{array}$ \\
\hline D-CMT1 & Darbeli CMT & 97 & 13,73 & 5,7 & 77 & 0,9339 \\
D-CMT2 & Darbeli CMT & 110 & 18,7 & 6,4 & 70 & 1,5868 \\
D-CMT3 & Darbeli CMT & 110 & 18,7 & 6,4 & 60 & 1,8513 \\
CMT-1 & CMT & 95 & 13,3 & 6,1 & 55 & 1,2218 \\
CMT-2 & CMT & 95 & 13,3 & 6,1 & 50 & 1,3645 \\
\hline
\end{tabular}

Kaynaklı birleştirme gerçekleştirildikten sonra mekanik testler için çekme deneyi numuneleri TS EN ISO 4136:2012 standartlarına göre hazırlanmıştır. Çekme deneyi Shimadzu $500 \mathrm{kN}$ universal test cihazında gerçekleştirilmiştir. Her kaynaklı birleştirmeden ikişer adet çekme numunesi hazırlanmış ve numuneler 10 $\mathrm{mm} / \mathrm{d}$ 'lık yükleme hızıyla çekilmiştir. Şekil 7'de gösterilen kıyaslama için esas malzemeye ait çekme mukavemeti değerleri EN 1999-1-1:2007+A1 standardından alınırken, kaynaklı numunelerin çekme mukavemeti değerleri çekme testi sonucunda elde edilen mekanik değerlerinin ortalamaları alınarak belirlenmiștir. Kaynaklı numunelere ait çekme testi sonuçları EN 1999-1-1:2007+A1 'de belirtilen karakteristik mukavemet değerlerinin üzerinde çıkmıştır. 
F. Kahraman vd. / Soğuk Metal Transfer (CMT) ve Darbeli Soğuk Metal Transfer (Darbeli CMT) Kaynak İşlemleri ile Birleştirilmiş AA5754 Alüminyum Alaşımının Mikroyapı ve Mekanik Özelliklerinin

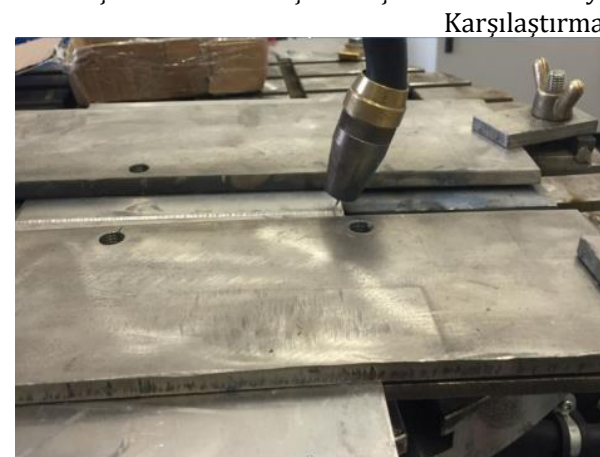

Şekil 3. Kaynak işleminden önce alüminyum levhaların sabitlenmesi

Kaynaklı birleștirmelerin kaynak bölgesindeki makro ve mikro yapılarını incelemek için numuneler kaynak yönüne dik doğrultuda çıkarılmıștır. Elde edilen numunelerin kesitleri, kum büyükleri $80-400-1200-2000$ olan SiC su zımparaları ile zımparalanmış ve ardından aşındırıcı partikül boyutları 1 $\mu \mathrm{m}$ olan elmas pasta kullanılarak parlatılmıştır. Dağlama işlemi için $20 \mathrm{~g}$ $\mathrm{NaOH}$ ve $100 \mathrm{ml} \mathrm{H}_{2} \mathrm{O}$ ile hazırlanan karışım sonrası Weck's dağlayıcısı kullanılmıștır. Mikrosertlik deneyleri $100 \mathrm{~g}$ 'llk yük $(\mathrm{HV} 0,1)$ ve 10 s'lik yük uygulama süresi kullanılarak gerçekleştirilmiştir.

\section{Bulgular}

Şekil 4'de farklı kaynak parametreleriyle kaynak edilmiş numunelerin kaynak dikişlerinin ve kaynak dikiş kesitlerinin makro görüntüleri verilmiştir. Darbeli CMT kaynak işleminde $0,9339 \mathrm{~kJ}$ lük bir isı girdisinin uygulandığı D-CMT1 numaralı numunede nüfuziyet eksikliği meydana gelmiştir. Benzer şekilde CMT kaynak işleminde de $1,2218 \mathrm{~kJ}$ 1sl girdisinin uygulandığı CMT1 numaralı numunede nüfuziyet eksikliği meydana gelmiștir. Yaklaşık olarak aynı miktardaki isı girdisi ile kaynak yapıldığında Darbeli CMT kaynak işleminde CMT kaynak işlemine göre daha az nüfuziyet eksikliği hatası oluşmaktadır. Diğer bir deyişle Darbeli CMT kaynak yöntemi daha yüksek nüfuziyete sahiptir.

\begin{abstract}
Makro muayene sonucunda nüfuziyet eksikliğinin olmadığı Darbeli CMT kaynak işleminde D-CMT2 ve D-CMT3 numaralı numunelerde, CMT kaynak işleminde ise CMT2 numaralı numunenin kaynak metallerinde numunelere göre farklı boyutlarda ve oranlarında gözenek oluştuğu gözlemlenmiștir.
\end{abstract}

Darbeli CMT işlemi ile birleștirilen DCMT2 ve D-CMT3 numaralı numunelerin kaynak metallerinde oluşan gözeneklerin CMT kaynak işlemi ile birleștirilen numunelerin kaynak metallerinde oluşan gözeneklere göre daha küçük çaplı olduğu tespit edilmiștir. Darbeli CMT kaynak işleminde kaynakta uygulanan ısı girdisi değerine bağlı olarak hem oluşan gözeneklerin çapları ve hem de dağılımı değişmektedir [12]. D-CMT2 numaralı numunede isı girdisinin relatif olarak DCMT3 numaralı numuneden düşük olmasına bağlı olarak katılaşma hızı artmış ve bunun sonucunda kaynak işleminde meydana gelen gazlar dışarıya çıkamadan katılaşma tamamlanmış ve daha iri çaplarda gaz boşluğuna neden olmuştur (Şekil 4b). Buna karşın D-CMT3 numaralı numunedeki kaynak metali katılaşma hızının daha yavaş olması, gazların daha fazla çıkmasına müsaade etmiş ve bu nedenle de daha küçük çaplarda gözenek oluşmuștur (Şekil 4c). Aynı zamanda ısı girdisi artışına bağlı olarak D-CMT3 numaralı numunede oluşan gözenek miktarı da azalmıştır.

CMT kaynak işlemi ile kaynak edilmiş CMT2 numaralı numuneye uygulanan isı girdisi D-CMT2 ve D-CMT3 numunelerine göre azdır. $\mathrm{Bu}$ durum CMT2 numunesinde relatif olarak daha fazla ve iri çapta gözenek oluşmasına sebep olmuştur.

Bunun yanında, D-CMT2 ve D-CMT3 numaralı numunelerde iyi kaynak kesit 
F. Kahraman vd. / Soğuk Metal Transfer (CMT) ve Darbeli Soğuk Metal Transfer (Darbeli CMT) Kaynak İşlemleri ile Birleștirilmiş AA5754 Alüminyum Alaşımının Mikroyapı ve Mekanik Özelliklerinin Karşılaştırmalı Olarak İncelenmesi

formu elde edilirken, CMT2 numaralı metali yığılmasının diğer numunelere numunenin kaynak dikişinde kaynak göre daha fazla olduğu gözlemlenmiștir.
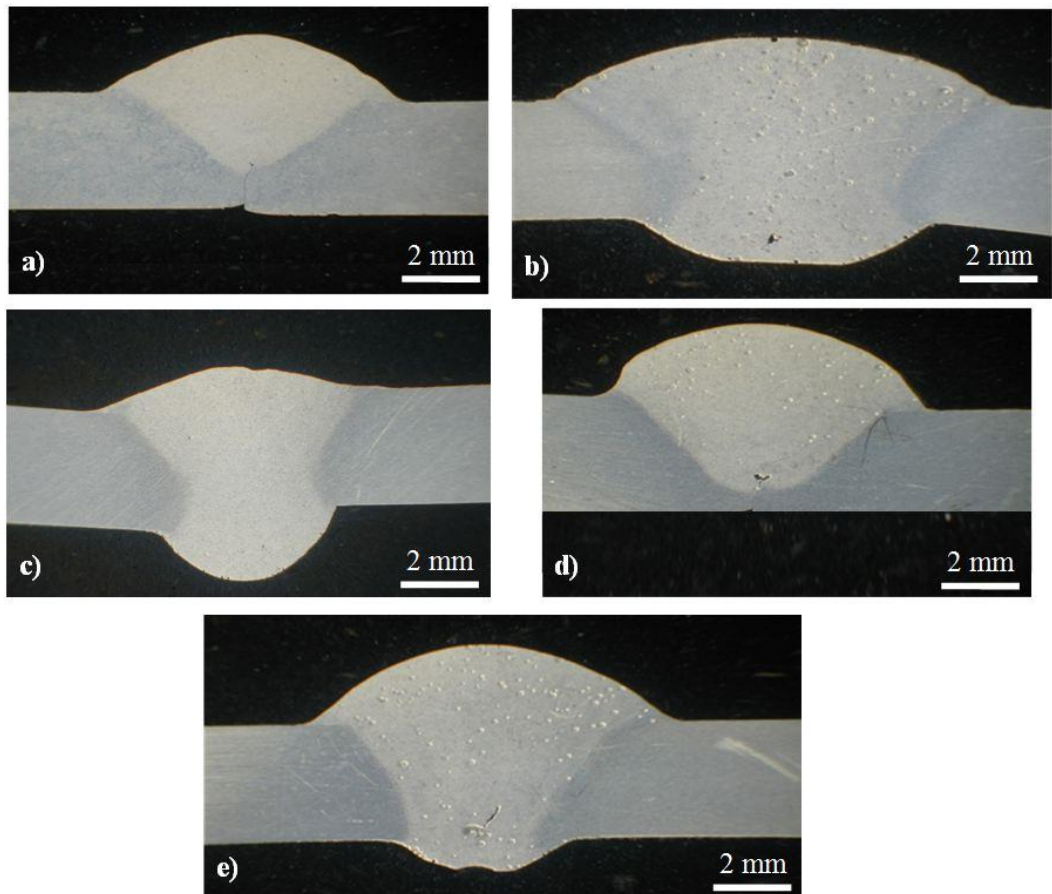

Şekil 4. Numunelerin kaynak kesitlerine ait makro fotoğraflar; (a) D-CMT1 numaralı numune; (b) D-CMT2 numaralı numune; (c) D-CMT3 numaralı numune; (d) CMT1 numaralı numune; (e) CMT2 numaralı numune

Gerek CMT ve gerekse de Darbeli CMT kaynak işlemlerinde Alüminyum ve alaşımlarının kaynağında kullanılan diğer gazaltı ark kaynağı yöntemlerine göre (MIG/MAG ve TIG) daha düşük ısı girdisi ile kaynak yapıldığından esas malzemenin de ısıya bağlı olarak etkilenme oranı azalmış ve bunun sonucunda da daha dar bir isı tesiri altındaki bölge (ITAB) oluşmuştur. Beklenildiği üzere oluşan bu ısı tesiri altındaki bölgenin (ITAB) genişliği ise ısı girdisi değerine göre değişmektedir. En geniş ITAB en yüksek isı girdisi ile gerçekleştirilen Darbeli CMT kaynak işlemi yapılan D-CMT3 numaralı numunede elde edilmiştir.

Şekil 5'de kaynak dikiş kesitlerine ait mikroyapı resimleri görülmektedir. Isı tesiri altındaki bölge (ITAB) de tane boyutları ısı girdisine bağlı olarak değişiklik göstermektedir. Darbeli CMT işlemi ile kaynak edilen numunelerde isı girdisi artışına bağlı olarak esas malzemeden başlayarak kaynak metaline doğru tane boyutu giderek irileşmektedir. Darbeli CMT yönteminde en fazla ıs girdisinin olduğu D-CMT3 numaralı numuneden daha fazla tane irileşmesi olduğu tespit edilmiştir.

Tüm numunelerde kaynak metali içerisinde dikiş merkezine doğru uzanan yönlenmiş sütunsal taneler mevcuttur (Şekil 5). ITAB'daki tane irileşmesine benzer şekilde kaynak metali içerisindeki sütunsal tanelerin de 
F. Kahraman vd. / Soğuk Metal Transfer (CMT) ve Darbeli Soğuk Metal Transfer (Darbeli CMT) Kaynak İșlemleri ile Birleștirilmiș AA5754 Alüminyum Alașımının Mikroyapı ve Mekanik Özelliklerinin

Karşlaştırmalı Olarak İncelenmesi
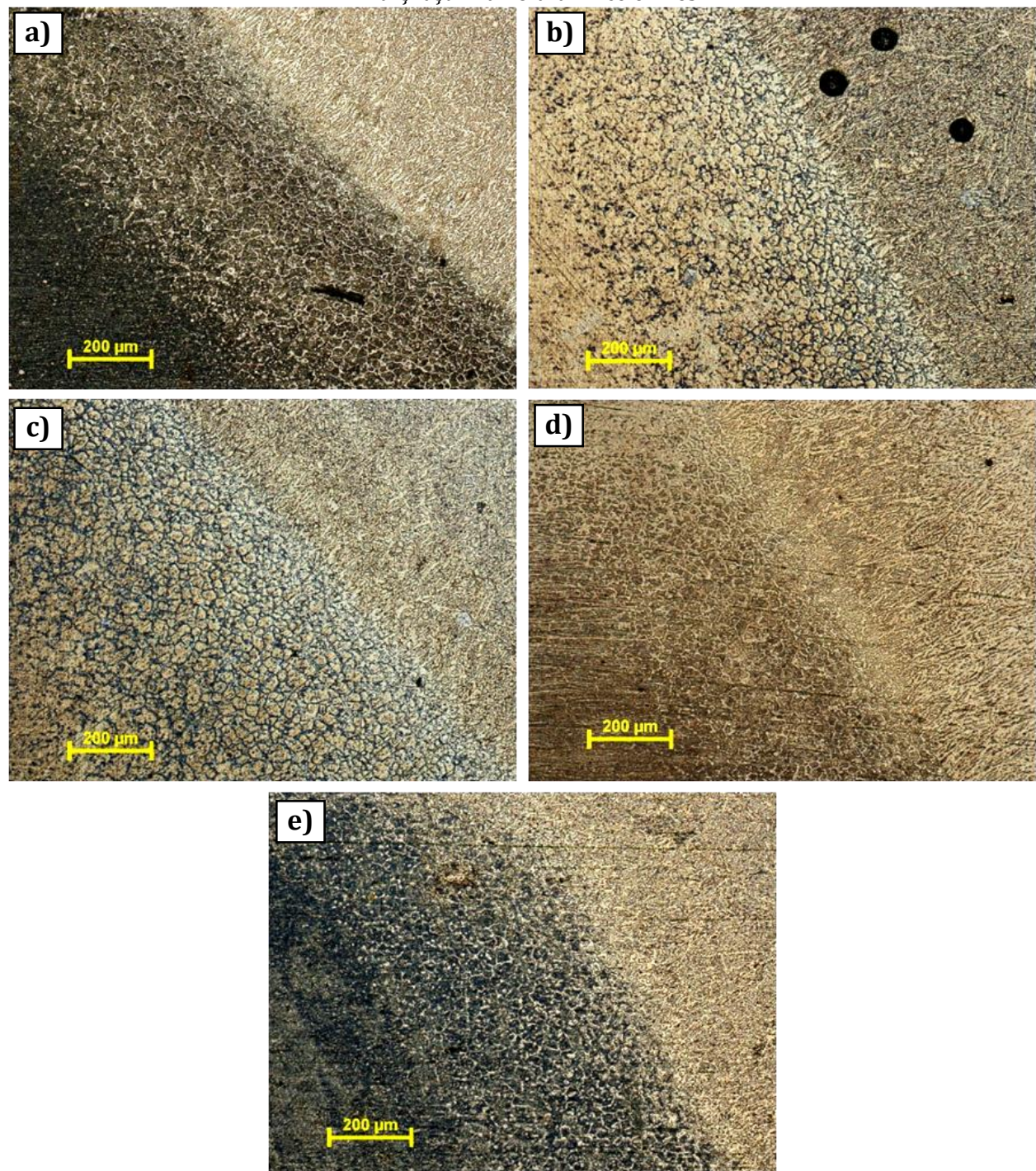

Şekil 5. Isıl girdiye bağlı olarak kaynaklı numunelerin ITAB ve kaynak metallerinde oluşan mikroyapılar; (a) D-CMT1 numaralı numune; (b) D-CMT2 numaralı numune; (c) D-CMT3 numaralı numune; (d) CMT1 numaralı numune; (e) CMT2 numaralı numune

boyutları ısı girdisine bağlı olarak değişmektedir. Darbeli CMT kaynak işlemlerinde ısı girdisi farkının daha fazla olması nedeniyle kaynak metali içerisindeki tane boyutu değişimi de daha belirgin bir şekilde ortaya çıkmaktadır (Şekil 6). Isı girdisinin daha düşük olduğu numunelerin kaynak metalinde meydana gelen tane irileşmesi ise çok daha düșük miktarlardadır.
Esas malzeme ve kaynaklı numunelere ait çekme deneyi sonuçları Şekil 7'de verilmiştir. EN 1999-1-1:2007+A1 standardında AA5754-H111 için belirtilen karakteristik değerler dikkate alınarak, kaynaklı numunelerin kaynak performansları (kaynaklı bağlantının maksimum çekme dayanımının esas malzeme çekme dayanımına oranı) DCMT2, D-CMT3 ve CMT2 numaral numuneler için sirasıyla; \%108,5, 
F. Kahraman vd. / Soğuk Metal Transfer (CMT) ve Darbeli Soğuk Metal Transfer (Darbeli CMT) Kaynak İşlemleri ile Birleștirilmiş AA5754 Alüminyum Alaşımının Mikroyapı ve Mekanik Özelliklerinin Karşılaştırmalı Olarak İncelenmesi

\%109,4 ve 105,5 olarak bulunmuştur. kopmadan önce plastik deformasyon Nüfuziyet eksikliğinin bulunmadı̆̆ (D- sonucu boyun verme meydana CMT2, D-CMT3 ve CMT2) tüm gelmiştir. Nüfuziyet eksiliğinin olduğu numuneler esas malzemeden (D-CMT1 ve CMT1) numuneler ise kopmuştur ve bu numunelerin hepsinde kaynak metalinden kopmuşlardır.
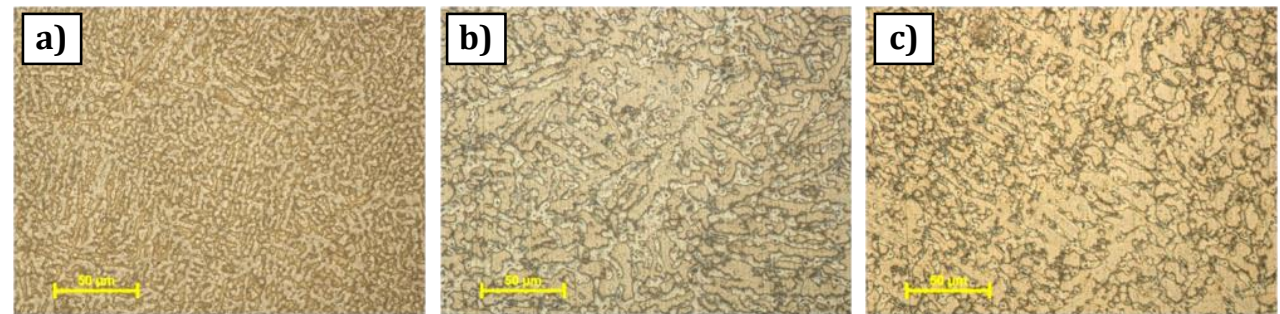

Şekil 6. Darbeli CMT kaynak işleminde ısı girdisine bağlı olarak kaynak metalinde oluşan tane boyutu değișimi; (a) D-CMT1 numaralı numune; (b) D-CMT2 numaralı numune; (c) D-CMT3 numaralı numune

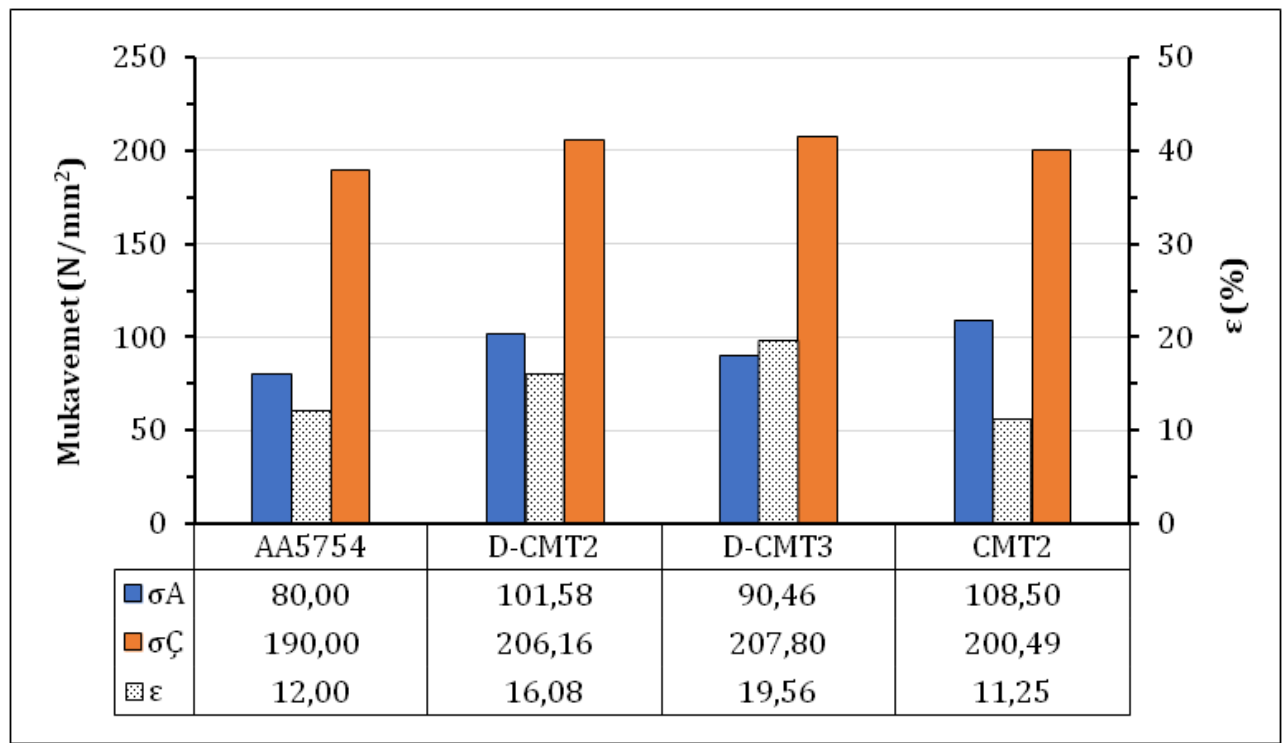

Şekil 7. Esas malzeme ve kaynaklı numunelerin ortalama çekme testi değerlerinin kıyaslaması

Darbeli CMT yöntemi ile birleştirilen DCMT2 ve D-CMT3 numaralı numunelerin makro görüntülerde tespit edilen gözeneklerin çok küçük ebatta olması ve kaynak metali içerisinde bir bölgeye yığılmaması (homojen dağılması) nedeni ile çekme deneyi değerlerini çok büyük bir oranda etkilemediği tespit edilmiştir.

Kaynaklı numunelerin kesitlerine ait sertlik profilleri Şekil 8'de görülmektedir. Kaynaklı numunelerin
Mikro Vickers sertlik ölçümleri numune kalınlıklarının ortasından gerçekleştirilmiştir. Ölçümler, kaynak metali ve esas malzeme bölgelerinden 1 mm aralıklarla, ITAB'dan ise $0,25 \mathrm{~mm}$ aralıklarla yapılmıştır. Numune kesitlerinin sertlik profillerine göre, tüm numunelerin kaynak metalleri en yüksek sertlik değerine sahiptir. Tüm numunelerde kaynak metali sertliği ortalama 65-70 HV olarak ölçülmüştür. Kaynak metallerinin sahip olduğu bu yüksek sertlik değerleri sadece kaynak 
F. Kahraman vd. / Soğuk Metal Transfer (CMT) ve Darbeli Soğuk Metal Transfer (Darbeli CMT) Kaynak İșlemleri ile Birleștirilmiș AA5754 Alüminyum Alașımının Mikroyapı ve Mekanik Özelliklerinin Karşılaştırmalı Olarak İncelenmesi

metali malzemesinden dolayı değil, aynı zamanda yüksek soğuma hızı (alüminyumun yüksek isıl iletkenli katsayısından dolayı) nedeniyle oluşan yüksek iç gerilmeler nedeniyle de meydana gelmektedir.

malzeme bölgelerine doğru sertlik değerlerinin düştüğü görülmektedir.

CMT ve Darbeli CMT kaynak işlemlerinde uygulanan kaynak işleminde diğer gazaltı kaynak yöntemlerine göre (MIG/MAG ve TIG) daha düşük ısı girdisi ile kaynak yapıldığından esas malzemenin de ısıya bağlı olarak etkilenme oranı azalmıştır. Bunun sonucunda esas malzemeden itibaren sertlik değișiminin kayda değer bir oranda olmadığı gözlemlenmiștir.

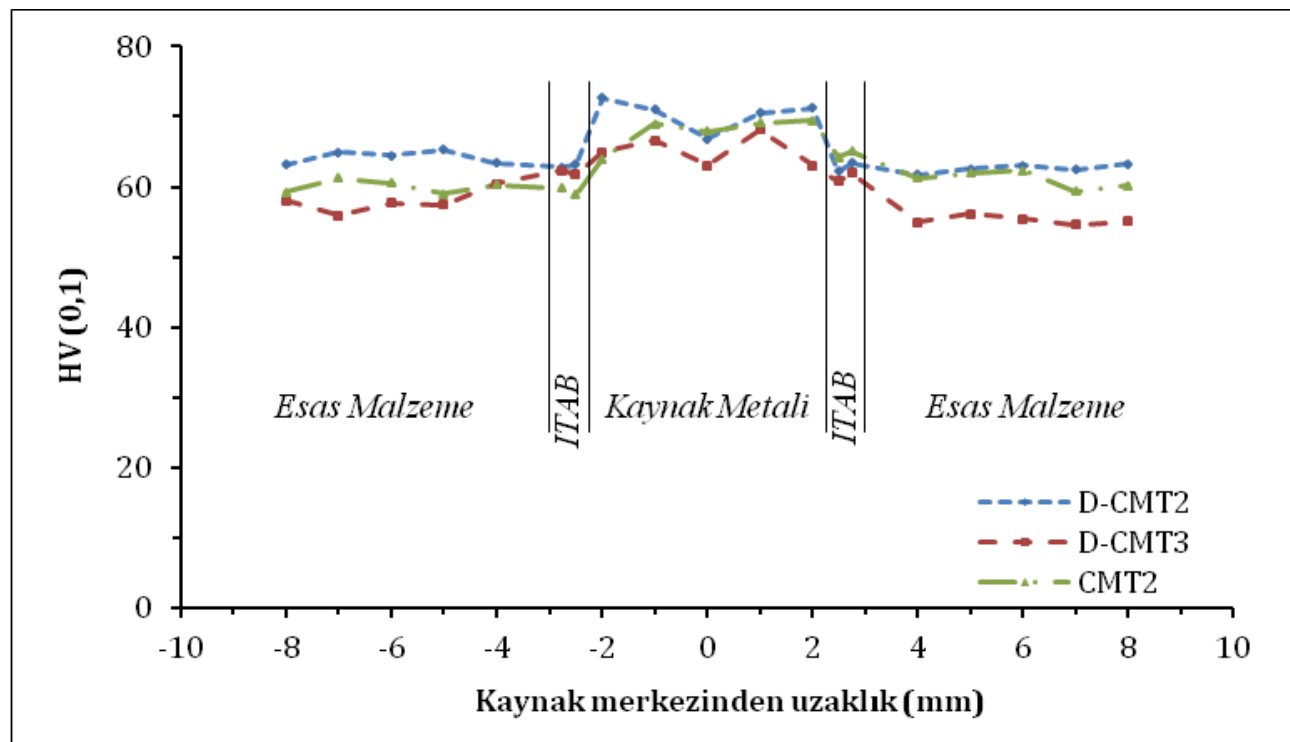

Şekil 8. Numune kesitlerinin sertlik profilleri

\section{Sonuçlar}

CMT yönteminin kullanıldı̆̆ CMT1 numaralı numune ile Darbeli CMT yönteminin kullanıldığı D-CMT1 numaralı numunede düşük ISı girdilerinin kullanılması nedeniyle numunelerde nüfuziyet eksikliği meydana gelmiştir. Ancak aynı miktardaki ısı girdisi ile kaynak işlemi yapıldığında nüfuziyet eksikliği hatası darbeli CMT kaynak işleminde CMT işlemine kıyasla daha az oluşmaktadır. Gerek CMT ve gerekse de Darbeli CMT kaynak ișlemlerinde alüminyum ve alaşımlarının kaynağında kullanılan diğer gazaltı ark kaynağı yöntemlerine göre (MIG/MAG ve TIG) daha düşük ısı girdisi ile kaynak yapıldığından daha dar bir ITAB oluşmuştur.

Darbeli CMT işleminin uygulandığ kaynaklı numunelerin kaynak metalinde meydana gelen gözeneklerin boyutları CMT işleminde oluşanlara kıyasla daha küçük olduğu tespit edilmiştir. Oluşan gözeneklerin hem boyutu ve hem de miktarı kullanılan ısı girdisinin azalmasına (katılaşmanın hızlanması nedeniyle) bağlı olarak artmaktadır.

Hem Darbeli CMT yöntemi hem de CMT yöntemi ile birleştirilen tüm numunelerin isı tesiri altında kalan bölgelerinde boyutları esas malzemeden 
F. Kahraman vd. / Soğuk Metal Transfer (CMT) ve Darbeli Soğuk Metal Transfer (Darbeli CMT) Kaynak İșlemleri ile Birleștirilmiș AA5754 Alüminyum Alaşımının Mikroyapı ve Mekanik Özelliklerinin Karşılaştırmalı Olarak İncelenmesi

kaynak dikişine doğru irileşen tane oluşumu meydana gelirken, kullanılan ısı girdisinin artmasına bağlı olarak kaynak metalinde sütunsal tane oluşumuna neden olmuştur. Bu tanelerin boyutlarının artan ISI girdisiyle birlikte arttığı tespit edilmiştir.

Çekme deneyleri sonucunda nüfuziyet eksikliğinin bulunduğu numunelerde kopma kaynak dikișlerinde meydana gelirken birleşmenin sağlandığı numunelerde kopma esas malzemede gerçekleşmiştir.

Hem Darbeli CMT hem de CMT yöntemi ile yapılan kaynak işlemlerinde isı girdisinin düşük olması ITAB'da esas malzemeye kiyasla sertliğin değişmemesini sağlamıştır. Tüm numunelerde en yüksek sertlik değerleri kaynak metalinde ölçülmüştür.

\section{Kaynakça}

[1] Taban, E., Kaluç, E. 2006. Microstructural and mechanical properties of double-sided MIG, TIG and friction stir welded 5083-H321 aluminium alloy: Kovove Materialy, Cilt. 44, s. 25-33.

[2] Yi, J., Cao, S.-f., Li, L.-X., Guo, P.-c., Liu, K.-y. 2015. Effect of welding current on morphology and microstructure of $\mathrm{Al}$ alloy T-joint in double-pulsed MIG welding: Trans. Nonferrous Met. Soc. China, Cilt. 25, s. 3204-3211. DOI: 10.1016/S1003-6326(15)63953-X

[3] Feng, J., Zhang, H., He, P. 2009. The CMT short-circuiting metal transfer process and its use in thin aluminium sheets welding: Materials and Design, Cilt. 30, s. 1850-1852. DOI: 10.1016/j.matdes.2008.07.015
[4] Abouarkoub, A., Thompson, G.E., Zhou, X., Scamans, G. 2015. Microstructure and Corrosion Properties of the Plasma-MIG Welded AA5754 Automotive Alloy: Journal of Minerals and Materials Characterization and Engineering, Cilt. 3, s. 318-325. DOI: 10.4236/jmmce.2015.34034

[5] Güngör, B., Kaluç, E., Taban, E., Şık, A. 2014. Mechanical and microstructural properties of robotic Cold Metal Transfer (CMT) welded 5083-H111 and 6082-T651 aluminum alloys: Materials and Design, Cilt. 54, s. 207-211. DOI: 10.1016/j.matdes.2013.08.018

[6] Shang, J., Wang, K., Zhou, Q., Zhang, D., Huang, J., Li, G. 2012. Microstructure characteristics and mechanical properties of cold metal transfer welding $\mathrm{Mg} / \mathrm{Al}$ dissimilar metals: Materials and Design, Cilt. 34, s. 559-565. DOI 10.1016/j.matdes.2011.05.008

[7] Barnes, T.A., Pashby, I.R., 2000. Joining techniques for aluminium spaceframes used in automobiles Part I - Solid and liquid phase welding: Journal of Materials Processing Technology, Cilt. 99, s. 62-71.

[8] Pickin, C.G., Williams, S.W., Lunt, M. 2011. Characterisation of the cold metal transfer (CMT) process and its application for low dilution cladding: Journal of Materials Processing Technology, Cilt. 211, s. 496-502. DOI: 10.1016/j.jmatprotec.2010.11.005

[9] Lorenzin, G., Rutili G. 2009. The innovative use of low heat input in welding: Experiences on 'cladding' and brazing using the CMT process: Welding International, Cilt. 23, s. 622-632.

DOI:10.1080/09507110802543252 
F. Kahraman vd. / Soğuk Metal Transfer (CMT) ve Darbeli Soğuk Metal Transfer (Darbeli CMT) Kaynak İşlemleri ile Birleştirilmiş AA5754 Alüminyum Alaşımının Mikroyapı ve Mekanik Özelliklerinin Karşılaştırmalı Olarak İncelenmesi

[10] Tapiola, J., 2017. Cold Metal Transfer Cladding of Wear And Corrosion Resistant Coatings In Engine Applications. Tampere University of Technology, Master of Science Thesis, 38s. Tampere.

[11] Fronius, 2014. Cold Metal Transfer. https://www3.fronius.com/cps/rde /xbcr/SID-9E5053B5-

33CBC666/fronius_international/M _06_0001_EN_leaflet_CMT_121_ww w_44211_snapshot.pdf (Erişim Tarihi: 11.10.2017)

[12] Sevük, A. 2007. Gazaltı Ark Kaynağında Sorunların Giderilmesi. Kaynak Tekniği Sanayi ve Ticaret A.Ş., I Istanbul, 10s. 